\title{
FAILURE OF UNION IN FRACTURE OF THE NECK OF THE FEMUR
}

\author{
A. J. HARrold, London, ENGland \\ From St Mary's Hospital, Paddington, London, and the Institute of Orthopaedics, \\ Royal National Orthopaedic Hospital, London and Stanmore
}

The treatment of patients with fracture of the neck of the femur is beset by many difficulties, medical and social as well as surgical. Of these difficulties failure of union is perhaps the most common, the most disabling and the most intractable. This paper outlines a hypothesis to explain the incidence of non-union in this and related injuries.

\section{THE HYPOTHESIS}

There is within synovial joints a system to preserve the joint cavity after injury. This system works by tending to prevent the coagulation of blood shed into the joint and by rapidly removing, without organisation, any clots that do form. It is suggested that the same system perpetuates the fracture gap in fractures that are wholly intra-articular.

The hypothesis is based on an analysis of the clinical features of the injury, and on two observations on the pathology, observations which have been supplemented by experimental and histological evidence.

\section{THE CLINICAL PROBLEM}

Non-union in complete, unimpacted, intracapsular fractures of the neck of the femur presents features not seen in most fractures elsewhere. Non-union is exceptionally common at this site. With treatment by nailing it has been reported in up to 50 per cent of cases (Eyre-Brook and Pridie 1941; Charnley, Blockey and Purser 1957). In a series of forty-one patients personally reviewed (Table I) non-union was clear in 37 per cent and suspected in a further 12 per cent.

TABLE I

Results of Nailing: Analysis of Fractures of the Neck of the Femur Treated at St Mary's Hospital 1950-55

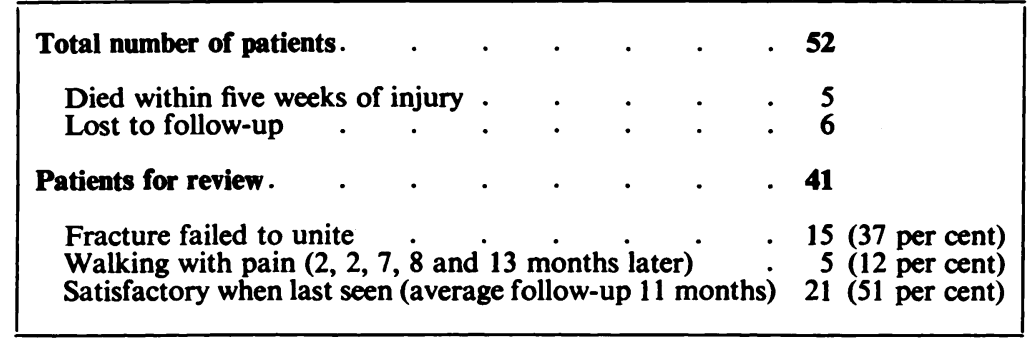

Preoccupation with the failure of many of these fractures to unite when treated has perhaps led to the more important question being overlooked - that is, the reason for the universal failure of union in untreated fractures. This injury is distinguished from other fractures by never uniting spontaneously-that is, when the patient is treated by simple rest of the injured limb in bed. Union is entirely dependent upon specially skilled treatment. There is nothing to make us suppose that non-union in treated cases has a cause different from that responsible for the non-union of untreated cases. 
In general, experience has shown that when the fracture is treated by internal fixation, if reduction is incomplete, union is not likely to follow (Lloyd 1938; Lewis, Boutelle and Roberts 1950; Cleveland and Fielding 1954). Imperfect reduction, which in most other fractures leads only to union in bad position, here is apt to produce complete failure of repair. Although small flaps of periosteum are sometimes caught between the fragments (Groves 1927, personal observations) the small amount of tissue available is never likely to constitute a serious barrier to reduction or union.

The successes so far obtained have been achieved by strictly immobilising the fragments. Partial immobilisation, as by traction in a Thomas's knee splint, although sufficient for trochanteric fractures and those of the shaft of the femur, is not enough for fractures of the neck of the femur: union here depends to an unusual degree on the strictness of immobilisation.

When non-union is manifest in spite of treatment, it commonly presents as a complete redisplacement of the fragments, very unlike the doubtful mobility of the ununited fracture of the shaft of a long bone. Finally, fractures of the neck of the femur, especially when union has failed, may show a remarkable "absorption" of bone from the two fracture surfaces, so that in time the femoral neck disappears.

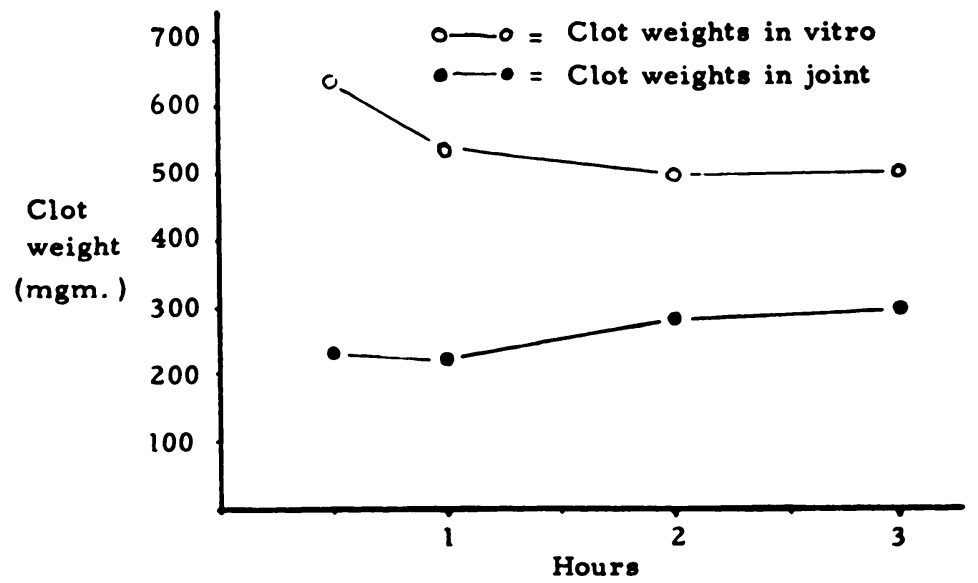

Fig. 1

Weights of clot obtained from one millilitre of blood allowed to clot in vitro (upper curve), and after injection into a joint (lower curve). Siliconed tubes with added thromboplastin were used for the series in vitro.

\section{THE BEHAVIOUR OF HAEMARTHROSES}

The first observation on the pathology concerns the fluid nature of blood shed into synovial joints. In clinical experience, although clots do sometimes form, such blood is usually found to be fluid. It may be aspirated and it flows out of the joint when it is opened at operation. Any clots that do form tend to disappear within a few days. Why this is so is not yet fully understood.

A short survey made in man showed, in nineteen joints explored within one week of injury, soft clots floating free or attached to injured surfaces in only nine. The clinical impression that there is a defect of coagulation has been supported by evidence from animal experiments, work which will be reported in detail elsewhere.

Comparison was made between the weight of clot formed from a standard volume of blood in vitro and after injection into the knee of a rabbit. The results are shown in Figure 1. The weights of clot formed in the joint were about half those obtained in vitro. Experiments performed in dogs showed a similar deficiency in the volume of clot formed (Table II).

Examination of the fluid component of experimental haemarthroses in the rabbit produced no evidence to suggest the presence of an anticoagulant (no increased concentration of 
antithrombin compared with that of defibrinated rabbit plasma). The haemarthrosis fluid was found to be unclottable because it was devoid of fibrinogen. Examination of human haemarthrosis fluid gave the same findings.

\section{TABLE II}

EXPERIMENTAL HaEMARTHROSES IN DOGS

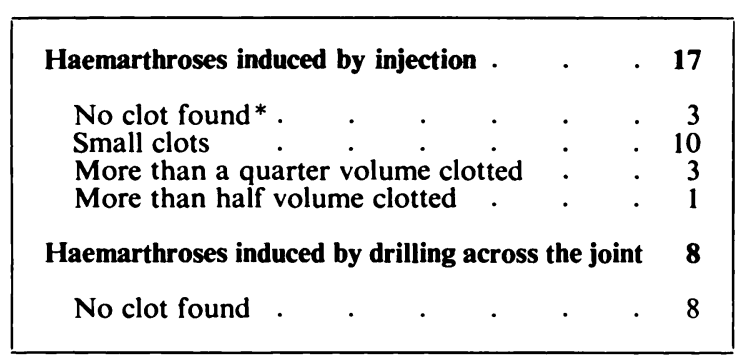

* The joints were explored at intervals of from five minutes to six hours after induction of the haemarthrosis.

When citrated plasma was injected into a rabbit knee the fibrinogen level of the fluid in the joint fell to zero within one and a half hours although very little or no clot was discoverable

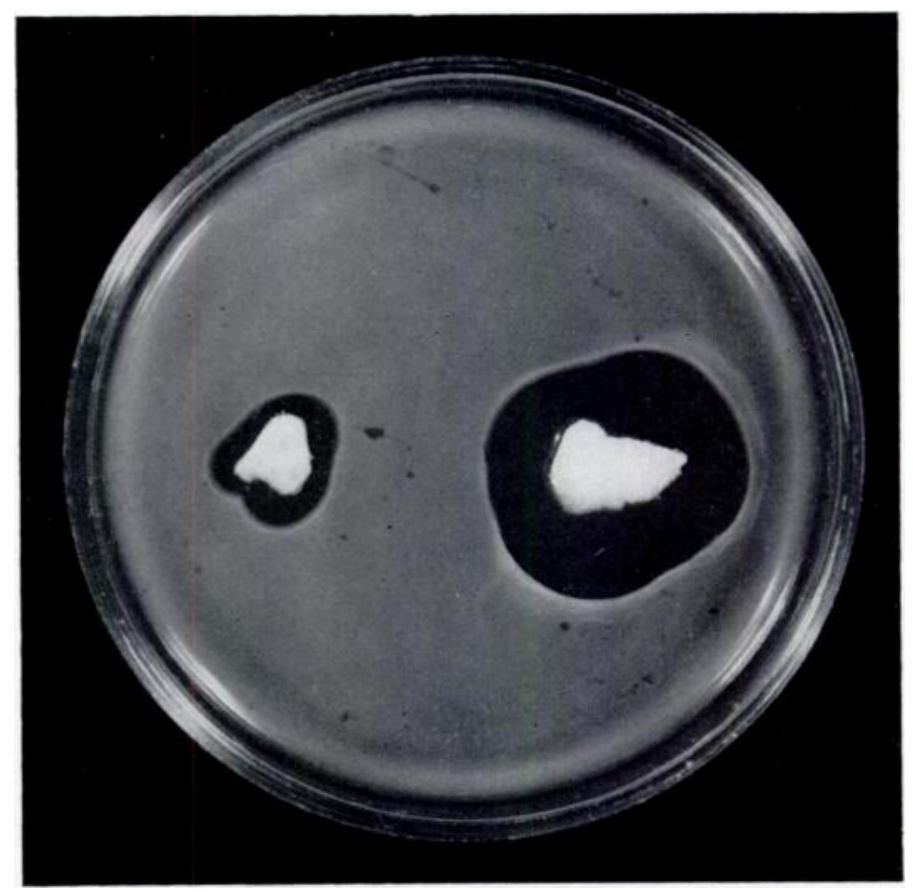

Fig. 2

A Petri dish containing a fibrin clot on which has been laid a piece of synovial membrane (right), and a piece of articular cartilage (left). After eighteen hours' incubation a zone of lysis of the clot has appeared around both tissues.

on opening the joint. With heparinised plasma no such fall in fibrinogen concentration occurred.

It has been realised for many years (Fleisher and Loeb 1915) that many tissues have the power to break down plasma clots. This property has been shown (Astrup and Permin 1947; 
Goldhaber, Cornman and Ormsbee 1947) to be due to the release of activators from the tissue concerned, substances which convert the pro-enzyme plasminogen in the plasma into the active protease, plasmin. The release of activator from articular cartilage (Lack 1959) and synovial membrane is readily demonstrable (Fig. 2). Plasmin will act on many substrates, fibrinogen as well as fibrin. Heparin is in most circumstances an inhibitor of plasmin. The disappearance of fibrinogen from citrate plasma but not from heparin plasma in a joint could thus be explained by the action of plasmin. It is indeed possible that both the deficiency of clot formation and the rapid disappearance of clots that do form in joints are caused by the physiological activation of plasmin by the joint tissues.

The absence of lasting clot in synovial joints prevents the formation of granulation tissue and so preserves the joint space and movement after injury.

\section{NON-UNION IS COMPLETE}

The second basic observation is that non-union in fracture of the neck of the femur is complete. No reparative tissue is found bridging the fracture gap (Fig. 3). This was noted by Santos (1930) and by Sherman and Phemister (1947), but its significance was not emphasised. The failure of repair involves fibrous tissue as well as bone. The twelve specimens in the present study in which there had been clinical failure of bony union all showed absence of fibrous union as well, although a proliferative tissue response was visible on one or both sides of the fracture gap. The only exception to this finding was the relatively late development of intraarticular adhesions, binding all structures in the joint together.

The completeness of non-union accounts for the complete redisplacement seen when osteosynthesis fails. It suggests that the failure of repair occurs at or before the stage of organisation of the fracture haematoma.

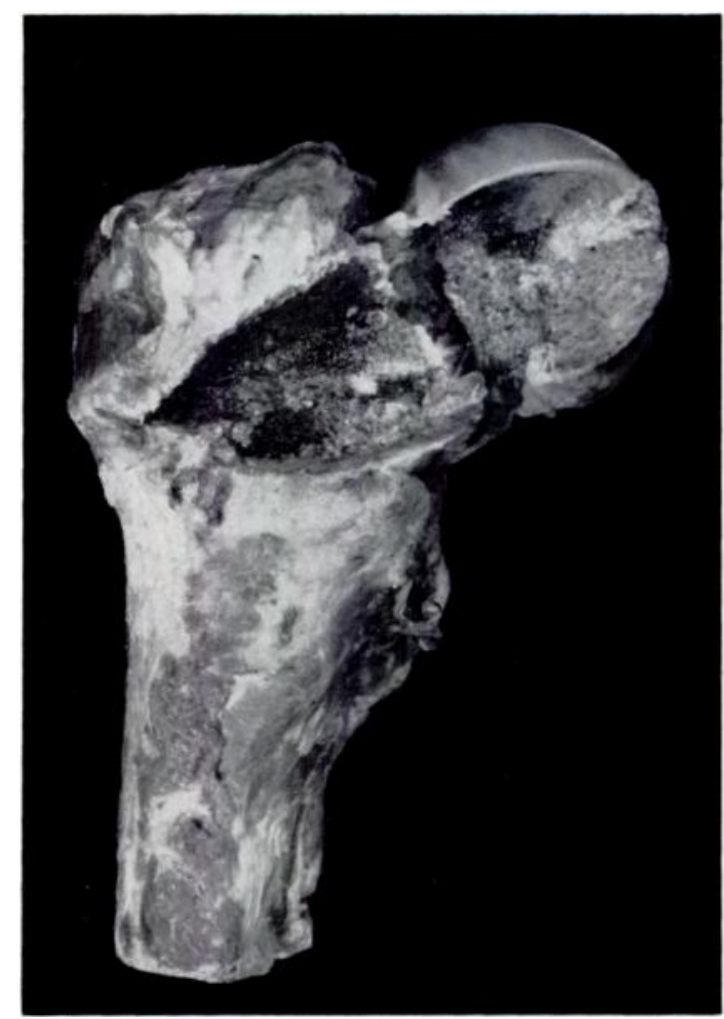

Fig. 3

An ununited fracture of the neck of the femur. The fragments are connected only by the soft-tissue hinge at the back.

\section{HISTOLOGICAL EVIDENCE}

Material from twenty-three patients with a fractured neck of femur was studied. In addition twelve recent fractures were explored at open operation. Comparison was made with material from selected fractures elsewhere.

On the first day the hip joint is distended by a viscous, bloody fluid. The fracture surfaces may be bare or covered by a thin layer of clot. Clot was generally absent by the fourth day in untreated fractures. From then on the fracture surfaces were covered only by debris (Figs. 4 and 5). Towards the end of the first week proliferation of cells was visible in the tissues next to the fracture. New bone could be seen by the end of the second week. The proliferating cells extended up to the stumps of the broken trabeculae, only occasionally extending farther as a fringe of granulation tissue. 
The specimens from all twelve patients with established clinical non-union showed widespread necrosis of the bone of the femoral head. In only six, however, did the sections examined show complete, or almost complete, necrosis of the marrow as well.

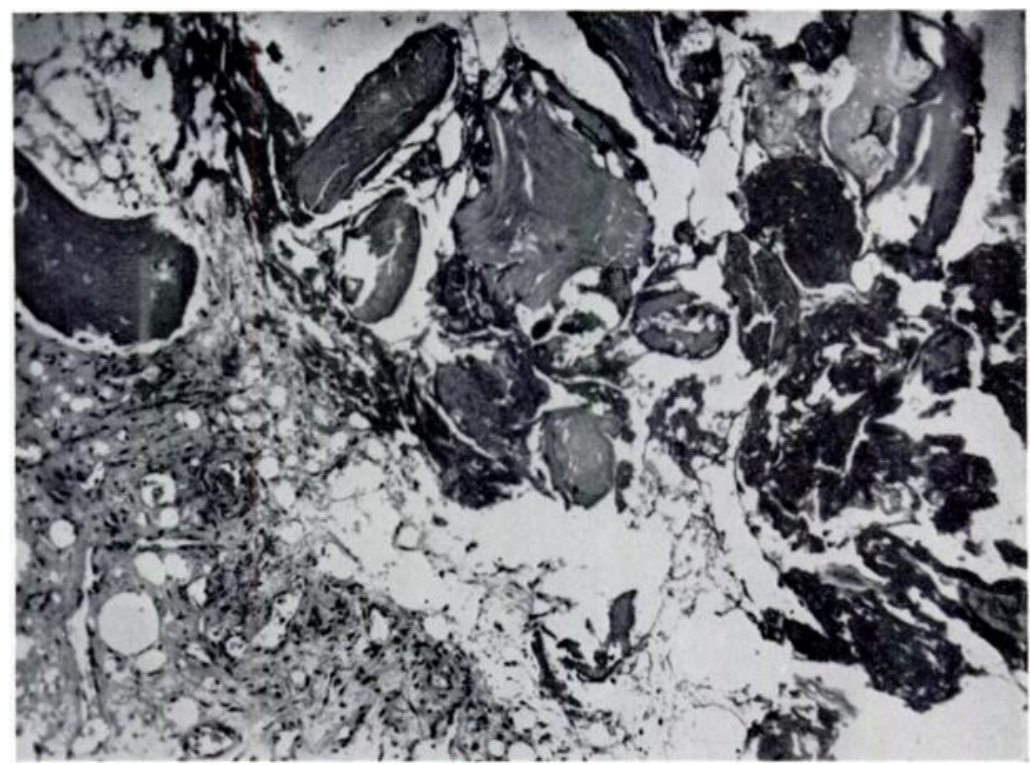

FIG. 4

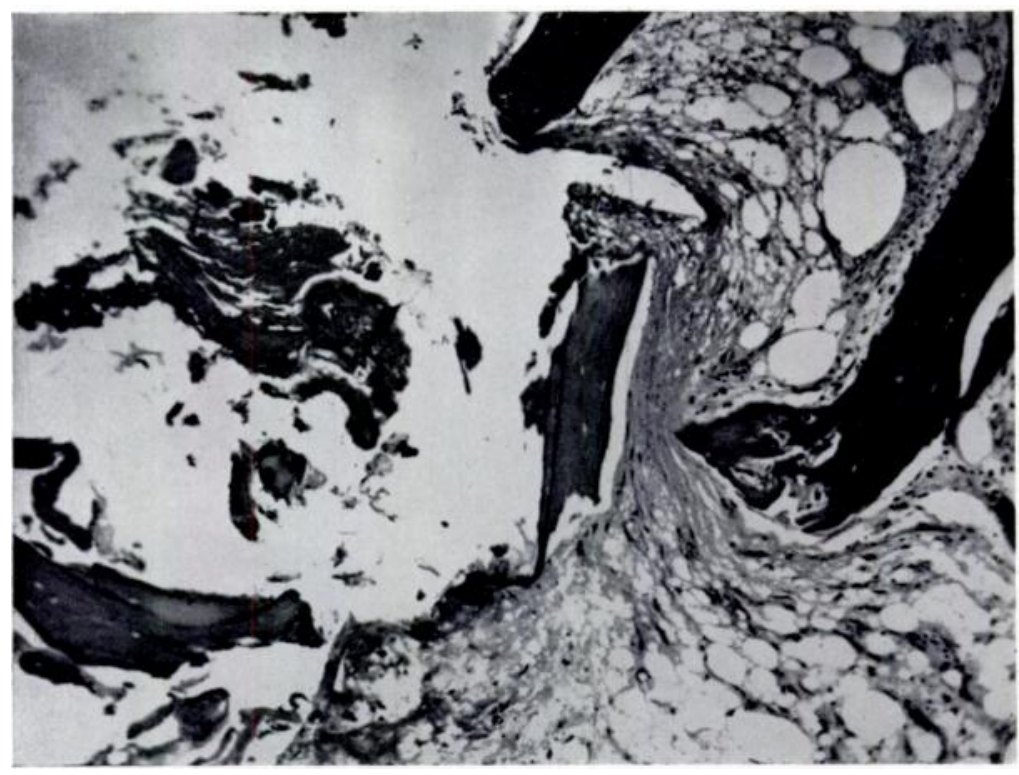

FiG. 5

The fracture surfaces from a fractured neck of femur eighteen days old. In both the proximal fragment (Fig. 4) and the distal fragment (Fig. 5) the surfaces are covered only by debris. The space between is filled by the effused fluid.

Bone necrosis was also seen regularly in the distal fragment, affecting the cortex more than the cancellous medulla.

Absorption of both fracture surfaces was seen even when the proximal fragment was completely ischaemic. Absorption thus seems to be independent of vascular and tissue 
responses at the fracture line. The macroscopic and histological appearances suggested rather that it was caused by simple friction between the fragments-friction allowed by the absence of fibrous union.

In a recent, well reduced femoral neck fracture the gap was found to be filled by a continuous clot, broken only by vacuoles of serum or fat, and containing fragments of bone debris. In a uniting fracture two months old a little unorganised clot was still present in the narrow gap, which was elsewhere bridged by callus (Fig. 6).

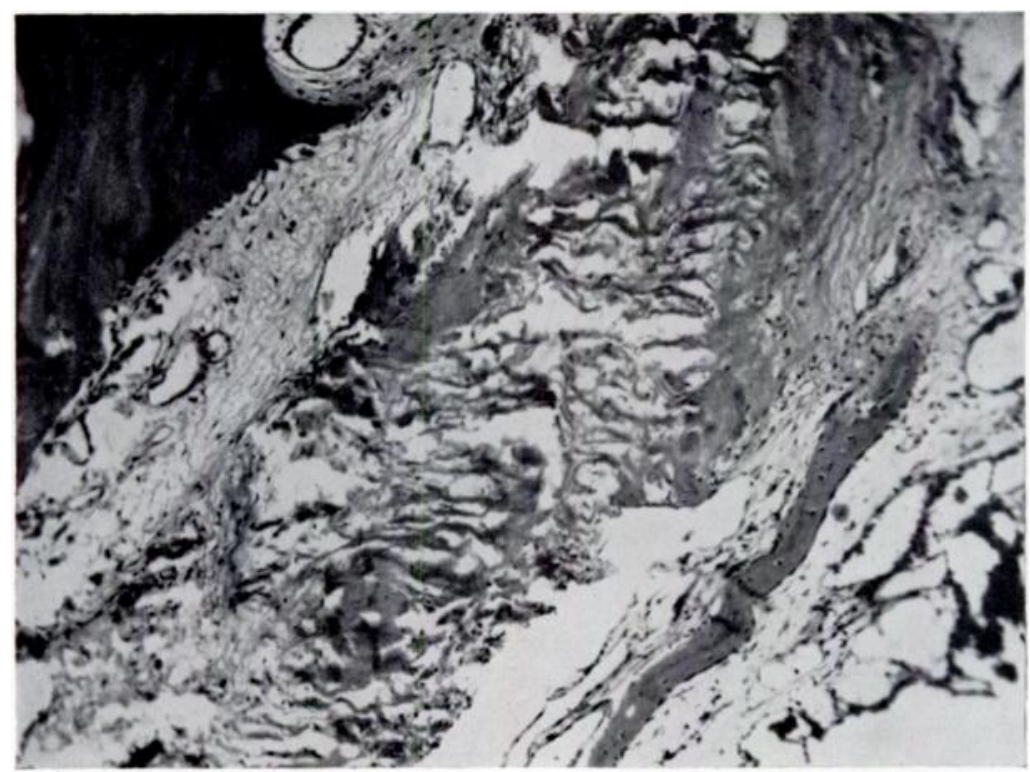

FiG. 6

A narrow zone of thrombus uniting the fragments of an adequately treated fracture of the neck of the femur two months after the injury. Elsewhere the fracture was united by young bone and connective tissue.

\section{DISCUSSION}

Union of fractures of the femoral neck occurs by direct adhesion of the bone ends, by the migration of cells from one fracture surface to the other, across the fracture gap. These cells cannot swim. To move they crawl, and they must have something solid to crawl upon (Harrison 1914, Abercrombie 1957). If the gap between the bone ends is filled by fluid (the unclotted joint effusion) it cannot be bridged by proliferating cells from either fragment. Non-union is complete.

Union can occur only if the fracture is closely reduced, so that the fracture surfaces are once more in contact, or at least so close that the gap between is filled by the thin layer of clot on the bone ends. Immobilisation must be strict so as not to break this fragile fibrin bridge over which the reparative cells migrate.

If, as may happen, the head fragment dies from damage to its blood supply, union can occur with almost equal facility by proliferation of cells from only one side of the gap, in the same way as an autogenous bone graft unites with the living bone against which it lies.

In extra-articular fractures conditions for union are less exacting. If the fracture is strictly immobilised from the start, the fracture haematoma may be rapidly organised and replaced by callus (Fig. 7). The clot between the fragments, however, is often broken up by movement, so that the bone ends lie in a cavity containing serous fluid. Union by first intention, by direct adhesion between the fracture surfaces, then cannot occur. The fracture unites instead by second intention. From the soft tissues surrounding the fracture haematoma a 
layer of granulation tissue and callus forms (Fig. 8). This layer thickens and gradually obliterates the fracture cavity by proliferation from the periphery (Urist and Johnson 1943, Charnley 1957).

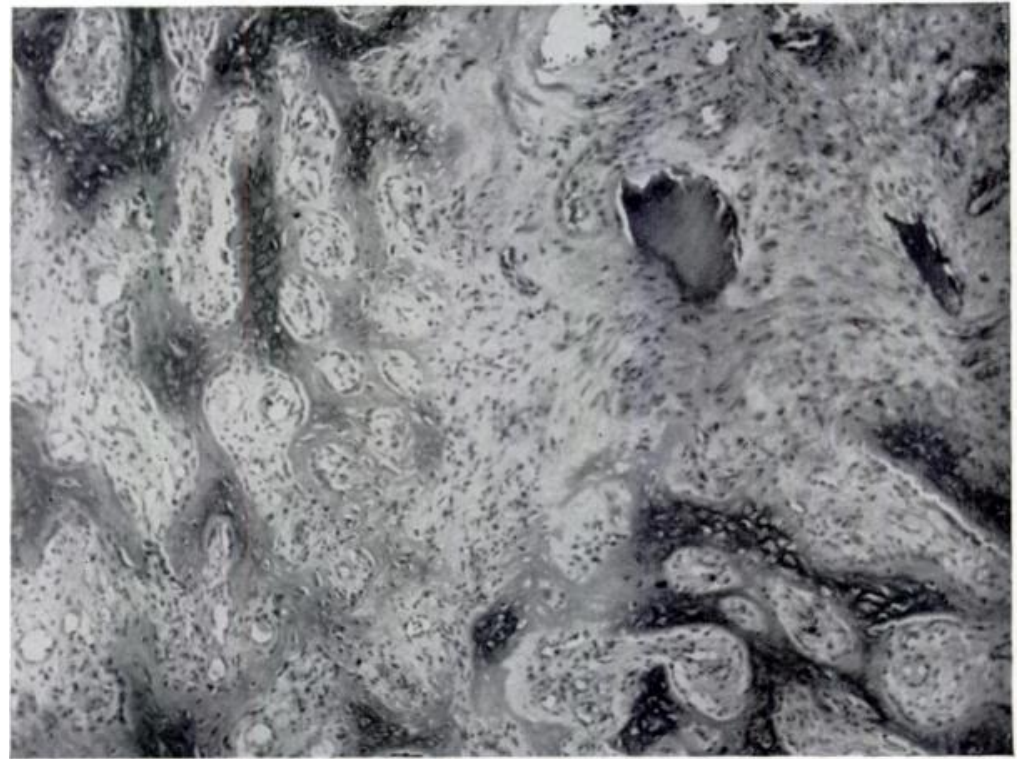

Fig. 7

Callus from a fractured shaft of tibia nineteen days old. The bone debris visible indicates that the callus has replaced the original fracture haematoma.

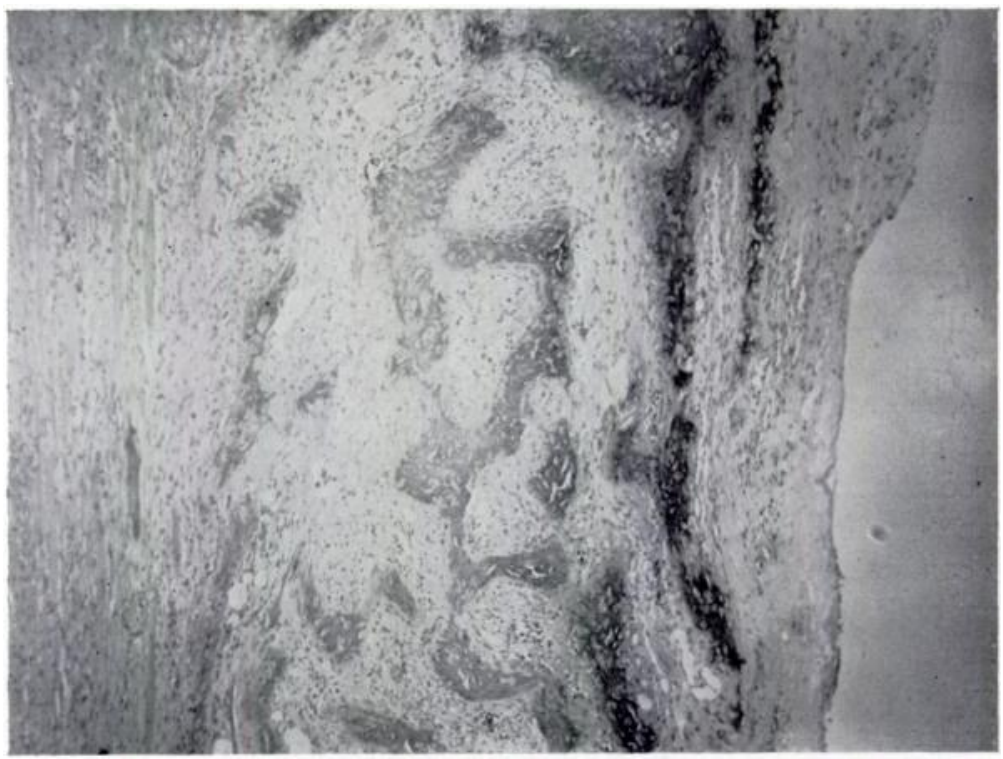

Fig. 8

The wall of the haematoma from a fractured shaft of humerus sixteen days old. From without in, muscle fibres, callus and granulation tissue can be seen.

Similar healing by second intention can occur in fractures exposed to a joint on one side, the fracture gap being filled by proliferation of tissues from its non-articular sides. Healing by second intention, however, cannot occur when a fracture is exposed to a joint on two 
opposing sides. Union then depends upon primary adhesion of the fracture surfaces which demands close reduction and complete immobilisation.

Other intra-articular fractures-These circumstances occur in two other important fractures, the behaviour of which lends support to the hypothesis.

The waist of the scaphoid bone is exposed on two sides to synovial joint (Fig. 9). Fractures here share with those of the femoral neck the distinction of rarely uniting without treatment.

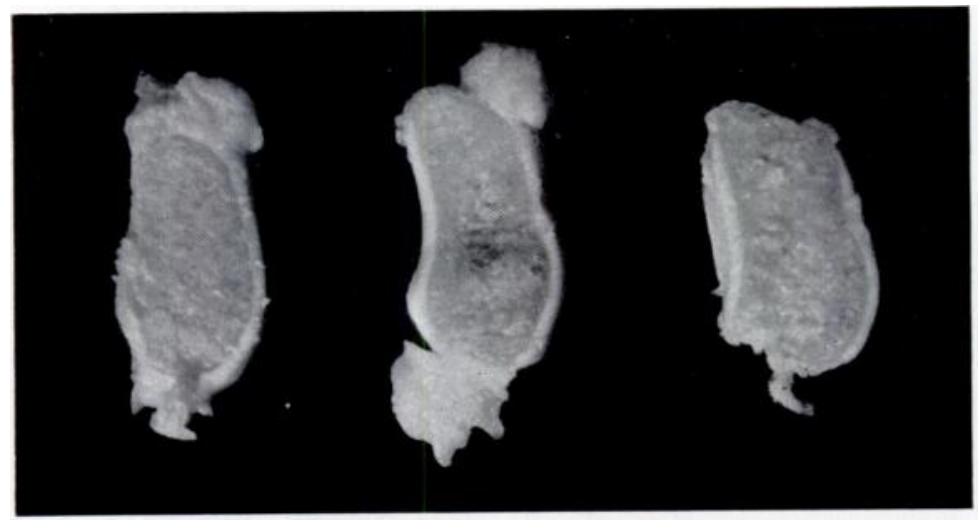

FIG. 9

Three slices across the waist of the scaphoid showing the extent of the articular surfaces. The most proximal slice is to the left.

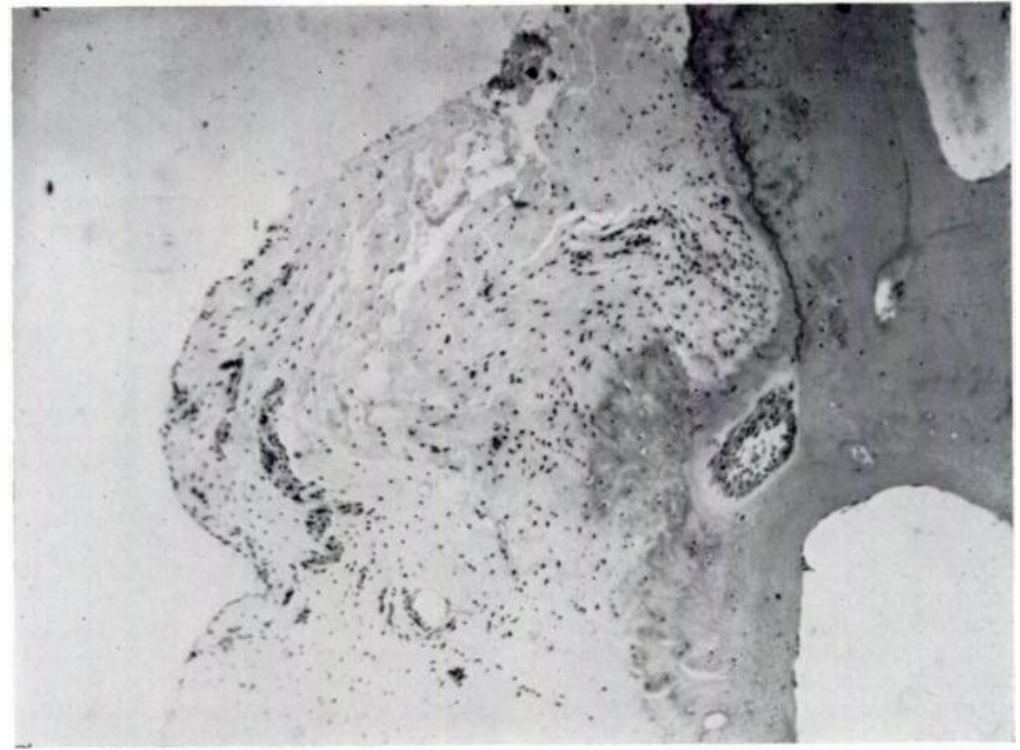

FIG. 10

Fibrous tissue lining the gap in an ununited fracture of the waist of the scaphoid: from the proximal fragment, twelve months after injury.

An apparently trivial crack has to be most strictly immobilised to secure union. Non-union, when it occurs, is absolute (Fig. 10). In recent fractures unclotted blood has been seen flushing the fracture gap (McLaughlin 1954).

Oblique fracture across the base of the lateral humeral condyle is almost the only fracture in children in which non-union is a problem. The importance of exact reduction and firm fixation has recently been emphasised (Jeffery 1958). When union fails, the fracture is 
completely ununited in its lower part (Cooper 1822). Oblique section of the lower end of the humerus shows the intra-articular position of most of the fracture line (Fig. 11).

\section{CONCLUSIONS}

The hypothesis provides a theoretical justification for, and re-emphasises the practical importance of, close reduction and strict immobilisation in the treatment of fractures of the neck of the femur. It does not support the view that failure of union is caused by vascular damage at the time of the original injury. Unexpected failure of union after nailing is more likely caused by unrecognised imperfection of reduction and the acknowledged deficiencies of internal fixation.

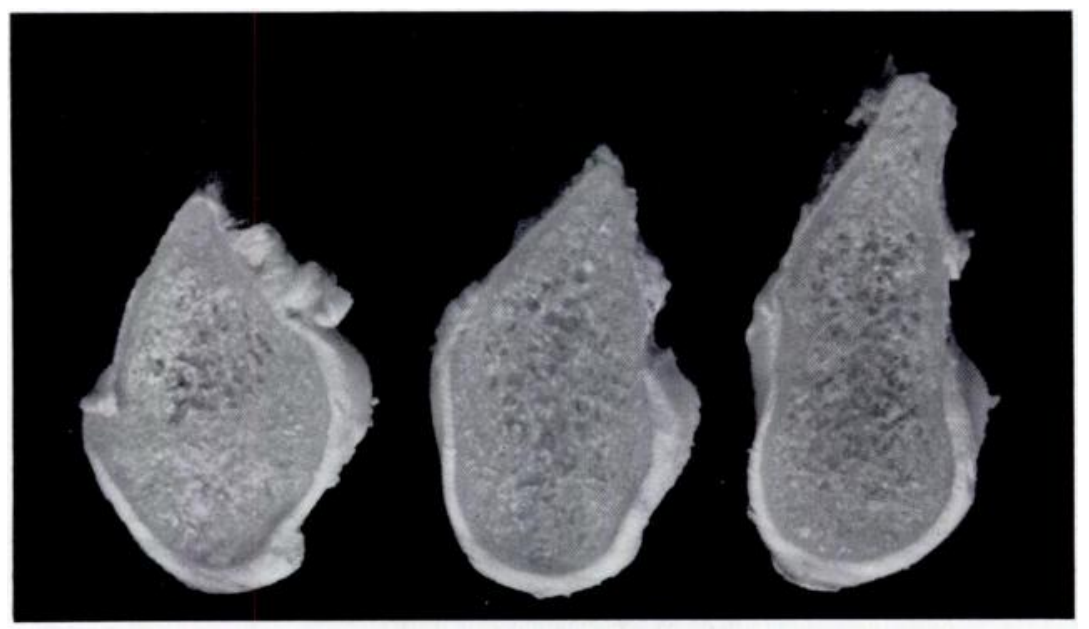

Fig. 11

Oblique slices across the base of the lateral humeral condyle, to show how fractures in this plane are partly intra-articular.

Attempts to improve results by passing the sartorius muscle around the fracture (Adams 1956), or by attaching muscle or joint capsule to the proximal fragment, have failed, because such soft tissues are swept off by the acetabular rim when the hip is flexed or medially rotated.

Further work is required, both on the more detailed biochemistry of haemarthroses and on the practical and wider implications of the hypothesis.

$\mathrm{Mr} \mathbf{J}$. Crawford Adams first called my attention to the possible role of the synovial fluid, and gave freely of help and encouragement in the development of the hypothesis. To him and to Mr G. L. W. Bonney I am very grateful for much excellent advice and for permission to report on their patients.

Dr C. K. Simpson and Mr B. Peirard helped in the collection of specimens. I am grateful to the Pathology Department of St Mary's Hospital for the histological preparations.

The cost of the experimental work on dogs was defrayed by a grant from the Joint Standing Research Committee, St Mary's Hospital and Medical School.

The biochemical investigations were carried out with the help, encouragement and supervision of $\mathrm{Dr} C$. $\mathrm{H}$. Lack in the Wellcome Research Laboratories, Institute of Orthopaedics. The cost of this work was met in part by a grant from the Joint Clinical Research Committee of the Royal National Orthopaedic Hospital and the Institute of Orthopaedics.

\section{REFERENCES}

Abercrombie, M. (1957): The Directed Movements of Fibroblasts: a Discussion. Proceedings of the Zoological Society, Calcutta, Mookerjee Memorial Volume, p. 129.

Adams, J. C. (1956): Personal communication.

Astrup, T., and Permin, P. M. (1947): Fibrinolysis in the Animal Organism. Nature, 159, 681.

Charnley, J. (1957): The Closed Treatment of Common Fractures. Second edition. Edinburgh and London:

E. \& S. Livingstone Ltd. 
Charnley, J., Blockey, N. J., and PUrser, D. W. (1957): The Treatment of Displaced Fractures of the Neck of the Femur by Compression. Journal of Bone and Joint Surgery, 39-B, 45.

Cleveland, M., and Fielding, J. W. (1954): A Continuing End-Result Study of Intracapsular Fracture of the Neck of the Femur. Journal of Bone and Joint Surgery, 36-A, 1,020.

COOPER, Sir A. (1822): A Treatise on Dislocations and on Fractures of the Joints. London: Longman Hurst, Rees, Orme and Brown.

Eyre-Brook, A. L., and Pridie, K. H. (1941): Intracapsular Fractures of the Neck of the Femur. British Journal of Surgery, 29, 115.

Fleisher, M. S., and LOeB, L. (1915): On Tissue Fibrinolysins. Journal of Biological Chemistry, 21, 477.

Goldhaber, P., Cornman, I., and Ormsbee, R. A. (1947): Experimental Alteration of the Ability of Tumor Cells to Lyse Plasma Clots in Vitro. Proceedings of the Society for Experimental Biology and Medicine, 66, 590.

Groves, E. W. H. (1927): Some Contributions to the Reconstructive Surgery of the Hip. British Journal of Surgery, 14, 486.

Harrison, R. G. (1914): The Reaction of Embryonic Cells to Solid Structures. Journal of Experimental Zoology, 17, 521.

Jeffery, C. C. (1958): Non-union of the Epiphysis of the Lateral Condyle of the Humerus. Journal of Bone and Joint Surgery, 40-B, 396.

LACK, C. H. (1959): Chondrolysis in Arthritis. Journal of Bone and Joint Surgery, 41-B, 384.

Lewis, K. M., Boutelle, W. E., and RoberTs, M. A. (1950): Intracapsular Fractures of the Neck of the Femur. Annals of Surgery, 131, 376.

Lloyd, E. I. (1938): To Nail or Not to Nail Abduction Fractures? British Medical Journal, i, 871.

McLaughlin, H. L. (1954): Fractures of the Carpal Navicular Bone. Journal of Bone and Joint Surgery, 36-A, 765.

Santos, J. V. (1930): Changes in the Head of the Femur after Complete Intracapsular Fractures of the Neck. Archives of Surgery, 21, 470.

Sherman, M. S., and Phemister, D. B. (1947): The Pathology of Ununited Fractures of the Neck of the Femur. Journal of Bone and Joint Surgery, 29, 19.

UrIST, M. R., and Johnson, R. W., Jun. (1943): The Healing of Fractures in Man under Clinical Conditions. Journal of Bone and Joint Surgery, 25, 375. 